\title{
Secundum atrial septal defect: routine surgical treatment is not of proven benefit
}

\author{
C Ward
}

The paper by Shah et $a l^{1}$ on page 224 in this issue of the British Heart fournal is one of several that have recently questioned the consensus policy for treating secundum atrial septal defect. $^{23}$

Secundum atrial septal defect accounts for $10 \%$ of congenital heart disease ${ }^{4}$ at birth and for $30-40 \%$ of cases seen in adults. $^{5}$ Approximately 300-400 patients undergo surgical closure of atrial septal defect in the United Kingdom each year.

Reports of the natural history of atrial septal defect and of the indications for and results of surgery imply that patients become increasingly symptomatic with advancing years, that surgical closure in childhood prevents this happening and in adult life reverses the deterioration. It is therefore widely but not universally ${ }^{6}$ advocated that atrial septal defects with a pulmonary to systemic flow ratio $>1.5$ :1 should be closed. ${ }^{5}$ The evidence to justify this policy is weak.

\section{Information on the natural history}

The first systematic account of atrial septal defect in 1934, which was an analysis of 62 post-mortem cases collected from published reports, examined information on the natural history in relation to clinical features, ${ }^{7}$ including precordial bulging and various systolic and diastolic murmurs attributed to associated mitral or tricuspid valve disease. Death, at an average age of 36 years, usually resulted from cardiac failure, often associated with atrial fibrillation. A much clearer and more detailed description of the clinical features, which appeared in $1941,{ }^{8}$ was an important landmark because it demonstrated that atrial septal defect was a specific clinical entity that could be diagnosed at the bedside with the aid of simple tests. Bedford et al detailed the classic radiological features of cardiomegaly, enlarged pulmonary arteries, hilar pulsation, and a small aortic knuckle that had been defined over the preceding 10 years $^{7}$ and summarised the electrocardiographic changes. They did not attempt to define the natural history but they did remark that most patients were breathless, that cardiac failure was rare before the third decade, and that when it occurred it was preceded by a period of 10-20 years of increasing exertional dyspnoea. The first reports written by Campbell et al with the specific objective of describing the natural history of atrial septal defects ${ }^{10}$ appeared in response to the article by Bedford et al. Campbell et al were particularly struck by the fact that during the first two decades of life though most patients had cardiomegaly their symptoms were mild and non-progressive. With one exception, a girl with mitral regurgitation, they had normal pulmonary artery pressures despite having large shunts. By the third decade, however, approximately a third of patients reported increasing breathlessness and some had a raised pulmonary artery pressure. This pattern of progressive disability continued and cardiac failure, atrial fibrillation, and pulmonary hypertension were increasingly common. Half the patients had symptoms by the age of 40 and by the age of 50 three quarters did. In the fifth and sixth decades most patients were severely disabled. In 1970 Campbell re-analysed and extended the data. ${ }^{10} \mathrm{He}$ calculated the annual mortality to be approximately $0.6 \%$ in the first and second decades, $6.3 \%$ in the fourth decade, and $9.4 \%$ in the sixth and subsequent decades. These findings form the basis of the commonly quoted figure that less than $50 \%$ of patients survive beyond the age of 50 . The next published report concentrated on the older age groups with a study of 67 patients seen from 1943 to 1963 all of whom had survived to the age of $40 .{ }^{11}$ Pulmonary hypertension was rare in young patients but increased in frequency with age: $30 \%$ of patients in the fifth and sixth decades had a pulmonary artery systolic pressure of $>50 \mathrm{~mm} \mathrm{Hg}$. Approximately $40 \%$ of patients had died or were seriously disabled in the fifth decade and $90 \%$ of survivors aged over 60 years were severely limited. Deterioration was attributed to atrial fibrillation, recurrent bronchitis, and pulmonary infarction. Disabled patients were more likely to have pulmonary hypertension and cardiac failure was common and often associated with atrial fibrillation. Systemic hypertension and chest infections contributed to the patients' deterioration in $20 \%$ of cases. The latest of the natural history reports (by Craig and Selzer) ${ }^{12}$ is the most detailed and provides haemodynamic and clinical data on 128 patients aged 18-56. Three quarters of their patients had symptoms. Most were dyspnoeic but fatigue and palpitations were also

\author{
Correspondence to: \\ Dr C Ward Department of \\ Cardiology, Wythenshawe \\ Hospital, Southmoor Road,
Manchester M23 9LT. \\ Accepted for publication \\ 23 November 1993 \\ Regional \\ Wynthenshawe
}


common. They noted, however, that "the great majority of patients did not consider themselves disabled and engaged easily in ordinary activities". This discrepancy between the subjective and objective assessment of symptoms goes some way towards explaining the wide variation in the reported incidence of symptoms. The pulmonary artery systolic pressure was greater than 25 $\mathrm{mm} \mathrm{Hg}$ in $60 \%$ of cases but only $15 \%$ had obstructive pulmonary hypertension (pulmonary vascular resistance $>5$ units)-this low percentage, compared with ventricular septal defect and patent ductus arteriosus has been noted by others. ${ }^{1314}$ The general observations of Craig and Selzer regarding progressive deterioration were similar to those of the earlier studies, although they concluded that pulmonary hypertension was the commonest single factor to presage worsening symptoms.

\section{Shortcomings of the data on natural history}

Though a fairly consistent clinical pattern emerges from these studies of the natural history of atrial septal defect, the data on which it is based are deficient. There are two major sources of error. Firstly, data relate predominantly to sick patients and secondly follow up information is inadequate. Patients were recruited for these early studies in the 1940 s and $50 \mathrm{~s}$ when the clinical recognition of atrial septal defect was in its infancy as was surgical treatment. It was therefore inevitable that the cases studied would be the most clinically obvious: for example most of the young patients had symptoms, albeit mild, whereas some later surgical series, which incorporated a wider range of cases, reported that most children were symptom free, ${ }^{15}$ and even in adult surgical series $50-70 \%$ were only mildly restricted $^{16}$ or not at all restricted. ${ }^{1}$ It was acknowledged that "the patients are far from the ideal of an unselected community" 10 and "small shunts cannot be clinically recognised, all patients had haemodynamically significant lesions". ${ }^{12}$ Even today it is accepted that the clinical diagnosis of the small atrial septal defect is difficult and many patients are referred to cardiac centres without a diagnosis, unless echocardiography has been performed. In two of the reports ${ }^{912}$ there was no follow up of patients: in one of these ${ }^{12}$ the authors "reconstructed the natural history" from their own observations and from other studies, notably those already quoted here. Campbell calculated mortality from patientyears of observation but the mean duration of follow up was only about $5 \cdot 2$ years. ${ }^{10}$ The duration of follow up in the other series ${ }^{11}$ was similar, and many of the patients were untraceable: 67 patients were seen at the age of 41-45 but only 47 aged $46-50$ and eight in the over 60 age group, though during this period only 11 were known to have died. Our understanding of the natural history of atrial septal defect is therefore based on an analysis of predominantly symptomatic patients who were either examined on a single occasion or were followed up for about five years. Conclusions drawn from such data must be guarded and are not applicable to unselected patients. We have no information on the long-term prognosis of symptom free children who are perhaps in the majority. ${ }^{15}$ Furthermore, the best information we have on symptom free adults with atrial septal defect comes from the accompanying report on page 224 from a major referral centre that would have attracted a selected patient population. Two potential sources of information on the incidence of small or asymptomatic atrial septal defects in an unselected adult population proved to be unhelpful. Firstly, an Australian case finding study based on miniature mass radiology, detected no examples of atrial septal defect in 111000 people aged over 65 years. ${ }^{17}$ The conclusion that this confirms the rarity of survival to this age ${ }^{12}$ is not justified for several reasons: (a) some patients with an atrial septal defect have a normal chest $x$ ray, (b) about $20-25 \%$ of the population of Australia at that time were immigrants $^{18}$ who had undergone chest $x$ ray examination before entry visas were granted, (c) Brigden reported that two out of 52 patients detected by miniature mass radiology were aged over 60 years, ${ }^{8}(d) \mathrm{Up}$ to $30 \%$ of adults with atrial septal defect have atypical radiological features. ${ }^{19}$ Also the incidence of atrial septal defect in routine postmortem examinations of adults is unknown.

\section{Causes of symptomatic deterioration and pathophysiology}

Although there are major gaps in the data on natural history it is valid to conclude that symptomatic patients become progressively more limited as they age (what is not known is the percentage of patients to whom this applies). Symptomatic deterioration has been attributed to the size of the defect, ${ }^{8}$ pulmonary hypertension, ${ }^{12}$ increasing pulmonary vascular resistance, ${ }^{20}$ atrial fibrillation, ${ }^{9}$ systemic hypertension, ${ }^{11}$ recurrent infections and reduced left ventricular compliance. ${ }^{21}$ Several reports have noted the frequent combination of atrial fibrillation and cardiac failure with increasing age. ${ }^{1011}$ Perloff concluded that a combination of reduced left ventricular compliance, atrial fibrillation, and mild to moderate pulmonary hypertension associated with a continuing large shunt is responsible. ${ }^{21}$ This is consistent with Harris and Heath's explanation $^{22}$ of the pathophysiology, which also explains why the natural history is so different from that of ventricular septal defect and of patent ductus arteriosus, where flow through the defect is determined by the difference in right and left ventricular systolic pressure and the size of the defect. With the fall in pulmonary artery pressure soon after birth, a dramatic increase in the left to right shunt leads to flooding of the lungs and to left ventricular failure. However, in atrial septal defect, a major determinant of flow is the relative distensibilities of the two ventricles in diastole which at birth are approximately 
equal. ${ }^{23}$ Consequently, at this time there is very little net flow across the defect. As a result the pulmonary artery pressure, as in the normal child, begins to fall and the right ventricle, which has less work to do, becomes thin walled and therefore more distensible. It is at this stage that shunting of blood from the left to the right atrium begins. This pattern becomes established in the teens when, it has been inferred, the adult balance between right and left ventricles is reached. ${ }^{24}$ The resulting increase in pulmonary blood flow therefore reaches a maximum after normal involution of the pulmonary arteries has been completed (this probably accounts for the extreme dilatation of the pulmonary arteries seen in the occasional patient with severe pulmonary vascular disease). There is now evidence ${ }^{25-28}$ that indicates that a combination of displacement of the interventricular septum to the left, caused by right ventricular overload, and decreased left ventricular preload resulting from the left to right shunt causes reversible (after surgery) reduction in left ventricular stroke volume. As a result of this the reninangiotensin-aldosterone system is activated, leading to an increase in intravascular fluid volume which in turn causes symptoms of congestion. When the chronically overloaded right ventricle eventually fails, the shunt size may in fact reduce if blood returning from the lungs can proceed in the normal direction through the left ventricle. However, because of the effects on left ventricular function mentioned above, or because of reduced left ventricular compliance resulting from hypertension or coronary artery disease with advancing age, this option may not be available.

\section{Results of surgery in children}

On the basis of the evidence from studies of natural history that symptomatic deterioration is almost inevitable with increasing age and that the average age of death is between 35 and 50 years, it was logical to advocate surgical repair in childhood to prevent complications. After the first reports of successful surgery, ${ }^{29} 30$ operative mortalities of $6-9 \%$ were achieved, ${ }^{31}{ }^{32}$ even before the advent of cardiopulmonary bypass though complications were significant, including a residual shunt in approximately $10 \%$ of cases. ${ }^{33}$ By the mid-1960s the operative mortality was $3 \% .^{34}$ Nowadays, it is less than $1 \%$ and incomplete closure is uncommon. However, in some reports morbidity and evidence of persisting cardiac impairment have been considerable. Junctional bradycardia, prolonged or persistent, occurs in $5-7 \%$ of cases. ${ }^{15}$ It has been inferred from chest $x$ rays, ${ }^{15}$ electrocardiography, ${ }^{35}$ and vectorcardiography ${ }^{36}$ that the heart size returns to normal over the course of six months to two years in most cases but cardiomegaly persisting for many years has also been described. ${ }^{15}$ Others have commented on both preoperative and postoperative left ventricular dysfunction ${ }^{37}$ but it is probably not clinically significant. ${ }^{15}$ The only postoperative follow up study that used echocardiography to monitor left ventricular function (and this was not in children) found no abnormality. ${ }^{1}$ Children operated on for atrial septal defect had a normal life expectancy, at least up until 27-32 years after the operation. ${ }^{13}$ However, in many series, ${ }^{13} 363839$ most children were symptom free preoperatively or else had a normal chest $x$ ray $^{15}$ and in such children the natural history is unknown.

\section{Results of surgery in adults}

Reports of surgical repair in adults also concluded that it is safe ${ }^{40-42}$ and results in considerable regression of symptoms in virtually all patients. The only contraindication is advanced pulmonary vascular disease. ${ }^{38}$ Nevertheless, operative mortality was usually greater than in children. ${ }^{132}$ This was attributed to age, preoperative cardiac failure, pulmonary hypertension, increased pulmonary vascular resistance, and atrial fibrillation. ${ }^{13} 3940$ In some reports, cardiac failure and pulmonary hypertension were associated with operative mortalities of $10-50 \%{ }^{4344}$ and even in more recent studies most operative deaths have been in these groups. In the comprehensive report by Murphy et $a l^{13}$ the operative mortality was $3.3 \%$ and all those who died were aged over 40 years. Not only is the operative mortality higher in adults than in children but late complications are more common and long-term survival is less than in controls. The actuarial survival at 27 years for patients operated on over the age of 25 was $40 \%$ compared with $59 \%$ for controls. ${ }^{13}$ Fifty nine per cent of patients in this age group had late events compared with $15 \%$ in younger patients: $42 \%$ of these complications were due to cardiac failure, $25 \%$ of patients had an embolic stroke (all were in atrial fibrillation) and $15 \%$ had either complete heart block or required pacemaker implantation. Others have also observed a high incidence of late embolic events. ${ }^{40} 45$

Despite the frequency of complications it has been concluded that surgically treated patients fare better than those treated medically. The evidence on which this conclusion is based does not stand up to close scrutiny. Firstly, these were not controlled studies and with one exception ${ }^{37}$ none of the authors indicated whether patients with advanced disease or with other complications were excluded from surgery. Secondly, at least with respect to symptoms, patients in the different surgical series were not comparable: the incidence of severe preoperative limitations ranged from $50 \%$ to $100 \%$. Furthermore, the symptomatic status of patients in the surgical and medical (natural history) series was different. This difficulty is compounded because not all authors used the New York Heart Association system: some simply quoted the incidence of symptoms. ${ }^{913}$ It is clear, however, that patients in some surgical series ${ }^{16}$ were significantly less symptomatic than medically treated patients. ${ }^{11}$ Other aspects of data presentation in the surgical reports preclude objective 
comparisons. Preoperative haemodynamic data are presented in different formats or not at all, ${ }^{38}$ the follow up period is variable, sometimes brief ${ }^{46}$ or not stated, ${ }^{44}$ and finally some authors do not mention postoperative complications such as atrial fibrillation, cardiac failure, and strokes. ${ }^{33} 4446$

In addition to these criticisms the longterm outcome in surgical series was always compared (favourably) with the previously discussed inadequate studies of natural history.

Two earlier reports also based their conclusions regarding appropriate treatment on a comparison of medically and surgically treated cases. ${ }^{1444}$ Steele $e t$ al found that after a minimum follow up of four years $20 \%$ of surgically treated patients and $71 \%$ of medical patients had died. ${ }^{14}$ Not surprisingly they concluded that, except for those in whom pulmonary vascular resistance was $>10$ units, surgery was the correct treatment. In the study reported by Wolf et al $20 \%$ of the surgical group died post operatively (most operations were done before the introduction of cardiopulmonary bypass), $25 \%$ died later, but $50 \%$ were improved. ${ }^{44}$ After an unstated time, $68 \%$ of traceable medical cases (11 of 16 ) were alive, nine of whom had minimal or no symptoms. In both of these studies patients in the medical group were more seriously ill. Despite deficiencies in the data, their conclusion, ${ }^{44}$ that surgical mortality in patients with severe pulmonary hypertension is high, is widely accepted. Their other conclusion, that symptom free adults may fare better with medical treatment, now finds support from Shah et al. ${ }^{1}$

Shah et al compared broadly similar groups of medically and surgically treated adults followed for 20 years. This was possible because for many years one of the authors did not routinely advise surgery. Patients in the surgical group had less severe symptoms than those in most previous reports, and this may explain the apparent lack of benefit from operative treatment. Surgical patients fared no better over the 20 years of follow up than medical cases with respect to mortality and to the incidence of breathlessness, atrial fibrillation, emboli, and cardiac failure. However, this still leaves several questions unanswered. (a) This is not a controlled study and the indications for inclusion in medical or surgical groups are not entirely clear. It is not, for example, explicitly stated that none of the patients treated by the "conservative" cardiologist had surgery. (b) It is unlikely that this centre studied an unselected group of patients. (c) By design, patients with advanced pulmonary vascular disease were not enrolled. Earlier studies indicate that this could have excluded $25-50 \%$ of cases who might have fared better with surgery than with medical treatment. (d) Twenty two percent of patients were lost to follow up. Despite its limitations this is the first report to cast serious doubt on the conventional policy for treating atrial septal defect in adults, doubts which were predictable from an assessment of the data on which the conventional policy is based.

In brief, neither the data on natural history nor the morbidity and survival figures from surgical results discussed here justify the claim that operation is better than conservative management.

\section{Conclusions}

There is objective evidence from the data on natural history and from surgical reports to justify repair of atrial septal defect in children with symptoms. This will restore functional capacity and life expectancy to normal at a very low operative mortality with only a small percentage developing late complications. Because we do not know the natural history of the condition in symptom free children there is no evidence that they should have surgery. They should, however, be reviewed annually to detect the onset of symptoms, which should be assessed objectively, and have echocardiography to indicate whether the shunt is increasing or whether pulmonary hypertension is developing. The onset of symptoms or of haemodynamic deterioration would warrant surgery. The age beyond which surgery should not be routinely offered is uncertain because the situation in adults is less clear than in children. However, it appears that surgery only restores life expectancy to normal before the age of $25^{13}$ and beyond that age, certainly in the less severely affected patients (in terms of symptoms and pulmonary artery pressure), surgery may offer no advantage. ${ }^{1}$

A rational approach to the management of atrial septal defect in adults, in particular those with symptoms, requires a controlled assessment of the relative merits of medical and surgical treatment.

1 Shah D, Azhar M, Oakley CM, et al. The natural history of medically and surgically treated adults with secundum atrial septal defect. A historical prospective study. Br Heart $\mathcal{F}$ 1994;71:224-8.

2 Konstantinides S, Geibel A, Kasper W, et al. The natural course of atrial septal defect in adults-a still unsettled issue. Klin Wochenschr 1991;69:506-10.

3 Cheng TO. The natural course of atrial septal defect in adults-a still unsettled issue. Clin Investig 1992;70:85.

4 Friedman WF In: Braunwald E, ed. Heart disease Philadelphia: Saunders, 1992:887-965.

5 Perloff JK. The clinical recognition of congenital heart disease. 3rd ed. Philadelphia: Saunders, 1987.

6 Moss AJ, Siassi B. The small atrial septal defect-operate or procrastinate? f Pediatr 1971;79:854-7.

7 Roesler H. Interatrial septal defect. Arch Int Med 1934; 54:339-80.

8 Bedford DE, Papp C, Parkinson J. Atrial septal defect $\mathrm{Br}$ Heart $\mathcal{F} 1941 ; 3: 37-67$.

9 Campbell M, Neill C, Suzman S. The prognosis of atrial septal defect. Br Med f 1957;i:1375-83.

10 Campbell M. Natural history of atrial septal defect. $\mathrm{Br}$ Heart $\mathcal{F}$ 1970;32:820-6.

11 Markman P, Howitt G, Wade EG. Atrial septal defect in the middle aged and elderly. $Q \mathcal{F} M e d 1965 ; 34: 409-26$.

12 Craig RJ, Selzer A. Natural history and prognosis of atrial septal defect. Circulation 1968;37:805-15.

13 Murphy JG, Gersh BJ, McGoon MD, et al. Longterm outcome after surgical repair of isolated atrial septal defect. $N$ Engl $\mathcal{F}$ Med 1990;323:1644-50.

14 Steele PM, Fuster V, Cohen M, et al. Isolated atrial septal defect with pulmonary vascular obstructive diseaselongterm follow-up and prediction of surgical outcom after surgical correction. Circulation 1987;76:1037-42.

15 Young D. Later results of closure of secundum atrial septal defect. Am $\mathcal{F}$ Cardiol 1973;31:14-22.

16 Nasrallah AT, Hall RJ, Garcia E, et al. Surgical repair of atrial septal defect in patients over 60 years of age. Circulation 1976;53:329-31. 
17 Seldon WA, Rubinstein C, Fraser AA. The incidence of atrial septal defect in adults. Br Heart $\mathcal{f}$ 1962;24: 557-60.

18 Australian Immigration Consolidated Statistics, 1990; No 16. Australian Bureau of Immigration and Population Research

19 Sanders C, Bittner V, Nath PH, et al. Atrial septal defect in older patients: Atypical radiographic appearances. Radiology 1988;167:123-7.

20 Dexter L. Atrial septal defect. Br Heart $\mathcal{f}$ 1956;18:209-25.

21 Perloff JK. Congenital heart disease in adults. In: Braunwald $\mathrm{E}$, ed. Heart disease. Philadelphia: WB Saunders, 1992:966-91.

22 Harris $P$, Heath $D$. The human pulmonary circulation. Edinburgh: Churchill Livingstone, 1986:308-28.

23 Keen EN. The post natal development of the human cardiac ventricles. $\mathcal{f}$ Anat $1955 ; 89: 484-502$.

24 Hollman A. Electrocardiographic diagnosis of right ventricular hypertrophy in infancy and childhood. $\mathrm{Br}$ Heart f 1958;20:129-36.

25 Bonow RO, Borer JS, Rosing DR, et al. Left ventricular functional reserve in adult patients with atrial septal defect: pre and post-operative studies. Circulation 1981;63:1315-22.

26 Carabello BA, Gash A, Mayers D, et al. Normal left ventricular function in adults with atrial septal defect and left heart failure. Am $\mathcal{F}$ Cardiol 1982;49:1868-73.

27 Booth DC, Wisenbaugh T, Smith M, et al. Left ventricular distensibility and passive elastic stiffness in atrial septal defect. $\mathcal{~}$ Am Coll Cardiol 1988;12:1231-6.

28 Borow KM, Karp R. Atrial septal defect: Lessons from the past, directions for the future. New Engl $₹$ Med. 1990; past, direction

29 Lewis FJ, Taufic $M$. Closure of atrial septal defects with aid of hypothermia: Experimental accomplishments and report of one successful case. Surgery 1953;33:52-9.

30 Gross RE, Watkins E Jr, Pomeranz AA, et al. A method for surgical closure of interauricular septal defect. Surg Gynecol Obstet 1953;96:1-23.

31 Lewis FJ, Winchell P, Bashour FA. Open repair of Atrial septal defects: Results in sixty three patients. $\mathcal{F} A M A$ 1957;165:922-7.

32 Kay EB, Zimmerman HA. Surgical treatment of atrial septal defect: Open versus close technics. Am $f$ Cardiol 1958;2:732-4.

33 Sellers RD, Ferlic RM, Sterns LP, et al. Secundum Type atrial septal defects: Early and late results of surgical repair using extracorporeal circulation in 275 patients. Surgery 1966;59:155-63.

34 Cohn LH, Morrow AG, Braunwald E. Operative treatment of atrial septal defect: Clinical and haemodynamic assessment in 175 patients. Br Heart $\mathcal{F} 1967 ; 29$ : 725-34.

35 Davies HK, Pryor R, Blount SG. Electrocardiographic changes in atrial septal defect following surgical correcchanges in atrial septal defect fol
tion. Br Heart $f 1960 ; 22: 274-80$.

36 Chabot M, Karamehmet A, Bourassa M, et al. Vectorcardiographic evaluation of post-operative changes in patients with interatrial septal defect. A review of 55 cases. Can Med Assoc F 1965;93:1340-5.

37 Saksena FB, Aldridge HE. Atrial septal defect in older patients. A clinical and haemodynamic study in patients operated on after age 35. Circulation 1970;42:1009-20.

38 Reed WA, Dunn MI. Longterm results of repair of atrial septal defect. Am F Surg 1971;121:724-7.

39 Horvath KA, Burke RP, Collins J, Jr, et al. Surgical treatment of adult atrial septal defect. $\mathcal{F} \mathrm{Am}$ Coll Cardiol ment of adult a

40 St John Sutton MG, Tajik AJ, McGoon DC. Atrial septal defect in patients ages 60 years or older: Operative results and longterm post-operative follow-up. Circulation 1981;64:402-9.

41 Richmond DE, Lowe JB, Barratt-Boyes BG. Results of surgical repair of atrial septal defects in the middle-aged and elderly. Thorax 1969;24:536-42.

42 Dave KS, Parkrashi BC, Wooler GH, et al. Atrial septal defect in adults. Clinical and haemodynamic results of surgery. Am $¥$ Cardiol 1973;31:7-13.

43 Gault JH, Morrow AG, Gay WA, et al. Atrial septal defect in patients over the age of forty years. Clinical and haemodynamic studies and the effects of operation. Circulation 1968;37:261-72.

44 Wolf PS, Vogel JH, Pryor R, Blount SG. Atrial septal defects in patients over 45 years of age. Merits of surgical versus medical therapy. Br Heart $¥ 1968 ; 30$ : 115-24.

45 Hawe A, Rastelli GC, Brandenburg O, et al. Embolic complications following repair of atrial septal defect. Circulation 1969;39(Suppl 1):185-91.

46 Hairston P, Parker EF, Arrants JE, et al. The adult atrial septal defect. Results of surgical repair. Ann Surg 1974;179:799-803. 